Anaesthesist $2022 \cdot 71$ (Suppl 2):S171-S179 https://doi.org/10.1007/s00101-021-01005-7 Received: 12 May 2021

Revised: 24 May 2021

Accepted: 31 May 2021

Published online: 22 July 2021

(c) Springer Medizin Verlag $\mathrm{GmbH}$, ein Teil von Springer Nature 2021

\section{Impact of the COVID-19 pandemic on emergency medical resources}

\author{
An observational multicenter study including all hospitals in \\ a major urban center of the Rhein-Ruhr metropolitan region
}

\begin{abstract}
Sebastian Bergrath ${ }^{1,2}$ (D) $\cdot$ Tobias Strapatsas $^{3} \cdot$ Michael Tuemen $^{4} \cdot$ Thorsten Reith $^{5}$. Marc Deussen ${ }^{6}$. Olaf Aretz ${ }^{1}$. Andreas Hohn ${ }^{7,8}$. Andreas Lahm ${ }^{9,10}$

'Zentrum für klinische Akut- und Notfallmedizin, Kliniken Maria Hilf, Akademisches Lehrkrankenhaus der RWTH Aachen, Mönchengladbach, Germany; ${ }^{2}$ Lehrstuhl für Anästhesiologie, Medizinische Fakultät, RWTH Aachen, Aachen, Germany; ${ }^{3}$ Zentrale Notaufnahme, Städtische Kliniken Mönchengladbach, Akademisches Lehrkrankenhaus der Heinrich-Heine-Universität Düsseldorf, Mönchengladbach, Germany; ${ }^{4}$ Zentrale Notaufnahme, Evangelisches Krankenhaus Bethesda, Mönchengladbach, Akademisches Lehrkrankenhaus der RWTH Aachen, Mönchengladbach, Germany; ${ }^{5}$ Zentrale Notaufnahme, Krankenhaus Neuwerk Maria von den Aposteln, Mönchengladbach, Akademisches Lehrkrankenhaus der RWTH Aachen, Mönchengladbach, Germany; ${ }^{6}$ Ärztliche Leitung Rettungsdienst, Berufsfeuerwehr Mönchengladbach, Mönchengladbach, Germany; ${ }^{7}$ Klinik für Anästhesiologie und operative Intensivmedizin, Kliniken Maria Hilf Mönchengladbach, Akademisches Lehrkrankenhaus der RWTH Aachen, Mönchengladbach, Germany; ${ }^{8}$ Medizinische Fakultät und Uniklinik, Klinik für Anästhesiologie und operative Intensivmedizin, Universität zu Köln, Köln, Germany; ${ }^{9}$ Klinikdirektion, Kliniken Maria Hilf GmbH Mönchengladbach, Akademisches Lehrkrankenhaus der RWTH Aachen, Aachen, Germany; ${ }^{10} \mathrm{Klinik}$ und Lehrstuhl für Orthopädie, Uniklinik RWTH Aachen, RWTH Aachen, Aachen, Germany
\end{abstract}

\section{Treten Sie in den Austausch}

Diese Arbeit wurde für Der Anaesthesist in Englisch eingereicht und angenommen. Die deutsche Zusammenfassung wurde daher etwas ausführlicher gestaltet. Sie finden diese an der Literatur des Artikels. Wenn Sie über die Zusammenfassung hinaus Fragen haben und mehr wissen wollen, nehmen Sie gern in Deutsch über die Korrespondenzadresse am Ende des Beitrags Kontakt auf. Die Autoren freuen sich auf den Austausch mit Ihnen.

\section{Introduction}

In week 9 of 2020, the coronavirus disease 2019 (COVID-19) reached the German region of Heinsberg and this region became an epidemic hotspot regarding infections with the severe respiratory distress syndrome coronavirus-2 (SARS-CoV-2) within a few days. The city of Mönchengladbach (274,096 residents, December 2019) is located nearby and has four academic teaching hospitals with different specializations and numbers of hospital beds (- Table 1).

The COVID-19 became a widespread problem in Germany in March 2020 so that multiple interventions were conducted to reduce virus spreading. Beside public interventions like social distancing, closure of restaurants, and nonfood stores, also inhospital interventions like a visiting ban were executed by national and local politicians. All hospitals in our city adapted their processes of outpatient and inpatient treatment and tried to expand their resources for the treatment of SARS-CoV-2 positive patients. Redistribution of in-hospital resources led to transformed processes and changed priorities in the allocation of hospital staff and hospital beds to ensure admission of SARS-CoV-2 positive and suspicious patients. It was already shown that in some German hospitals, mainly university hospitals, the number of emergency department (ED) visits dropped significantly [14]. These hospitals were specialized hospitals in different regions of the country. It remained unclear how the COVID-19 outbreak influenced a whole metropolitan area with its complete hospital resources and how ED 
patient characteristics differed compared to the pre-COVID period.

Against this background, we carried out a retrospective multicenter pre-post study to analyze how the local COVID-19 outbreak influenced the systemic parameters and emergency medicine indicators of all acute hospitals in an entire German city.

\section{Methods \\ Study design}

This observational multicenter analysis was performed retrospectively after the first wave of SARS-CoV-2 infections in Germany. All data were collected prospectively in the medical controlling departments and the hospital information systems of the participating hospitals. To evaluate the possible influences of the COVID-19 outbreak, the time period from weeks 4-24 in 2020 was compared with the corresponding period in 2019.

\section{Study sites}

All acute care hospitals in the city of Mönchengladbach, Germany, participated (- Table 1). Every hospital runs an ED and 1-5 intensive care units (ICU).

\section{Outcomes}

The following parameters and key figures were analyzed for each hospital as well as for the whole city in a pooled analysis:

- total number of ED visits

- number of hospital admissions from the ED

- number of outpatient contacts in the ED

- hospital admissions related to the different medical specialties

- number of ICU admissions from the ED

- number of occupational accidents

These parameters are shown in relation to the time of the following events: appearance of the first SARS-CoV-2 cases in the region, social distancing measures, case numbers of SARS-CoV-2 positive patients in Mönchengladbach and Easter holidays.

The medical disciplines are summarized as follows: internal medicine, including all subspecialties; traumatology;

Background: With the coronavirus disease 2019 (COVID-19) outbreak hospitals prepared for increasing numbers of patients without knowing how patient populations were evolving and what resources would be required. The present study aimed to analyze the impact of the local COVID-19 pandemic on emergency resources of all hospitals in a major urban center (Mönchengladbach) in Germany.

Methods: This observational multicenter study involved all acute care hospitals $(n=4)$. Systemic emergency department (ED) parameters from weeks 4-24 in 2020 were compared to the corresponding period in 2019 for each hospital and in a summative data analysis using a logistic regression model.

Results: The first regional COVID-19 patients were detected in week 9 of 2020. The cumulative number of ED visits dropped from 34,659 in 2019 to 28,008 in 2020 . Weekly ED visits per hospital decreased from week 8 onwards between $38 \%$ and $48 \%$ per week and hospital and began to rise again after week 16 . The pooled data analysis of ED patients showed significant decreases in outpatient visits $(20,152$ vs. $16,477, p<0.001)$, hospital admissions $(14,507$ vs. $11,531, p<0.001)$, and work-related accidents ( $2290 \mathrm{vs.}$ $1468, p<0.001$ ). The decrease in ED to ICU admissions showed no significance (2093 vs. $1566, p=0.255$ ). The decline in ED cases was equally distributed between the medical specialties.

Conclusion: The regional COVID-19 outbreak led to significantly reduced ED contacts in a German major urban region after the first COVID-19 cases appeared. Both hospital admissions and the number of ED to ICU admissions decreased, whereas the ratio of emergency outpatients vs. inpatients remained stable. Therefore, it can be assumed that patients with severe medical problems did not seek emergency care. These secondary effects of the pandemic on healthcare and the socioeconomic impact should be analyzed further.

\section{Keywords}

COVID-19 · Emergency department · Outpatient visits · Inpatient admissions · Intensive care unit · Working accidents

surgery other than traumatology (visceral surgery, vascular surgery, plastic surgery, spine surgery) and others (including gynecology and obstetrics, urology, pediatrics, ear nose and throat, ENT medicine, geriatrics, nuclear medicine, therapeutic radiology).

\section{Ethical approval}

Data collection was performed after ethical approval by the ethics committee of the University Hospital RWTH Aachen, Germany (EK 251/20) and registration at the Clinical Trials Center Aachen (registration number CTC-A 20-297) was conducted.

\section{Data sources and statistical analyses}

Data were retrieved from the medical controlling department (Kliniken Maria Hilf) or from the hospital information system using a data export tool (all other hospitals) and transferred to an Excel database (Excel, Microsoft Corp., Redmond, WA, USA). Data comprised no personal patient data. Data of the local COVID-19 numbers were retrieved from the Center of Health of the State of North Rhine-Westphalia and from the information system of security of the State of North Rhine-Westphalia [7, 8].

We conducted a local polynomial regression. Statistical analyses were performed using R software (V. 4.02; R Core Team, Vienna, Austria, https://www.Rproject.org/). Data related to the first COVID-19 outbreak from weeks 4-24 in 2020 were compared to the corresponding period in 2019 using $x^{2}$-test for each hospital for the whole period and in weekly periods. When multiple comparisons were calculated, Bonferroni-Holm correction was used to adjust $p$-values. To account for local peculiarities, we pooled all data and compared both periods for all city hospitals data.

\section{Results}

All hospital executives, city officials and fire department executives met weekly during this outbreak. The hospitals adapted their admission strategy with postponement of elective admission for operations, 


\begin{tabular}{|c|c|c|c|c|}
\hline Hospital/parameters & $\begin{array}{l}\text { Evangelisches } \\
\text { Krankenhaus Bethesda } \\
\text { (Hospital 1) }\end{array}$ & $\begin{array}{l}\text { Städtische Kliniken Mön- } \\
\text { chengladbach St. Elisabeth } \\
\text { (Hospital 2) }\end{array}$ & $\begin{array}{l}\text { Kliniken Maria Hilf } \\
\text { (Hospital 3) }\end{array}$ & $\begin{array}{l}\text { Krankenhaus Neuwerk } \\
\text { "Maria von den Aposteln" } \\
\text { (Hospital 4) }\end{array}$ \\
\hline Number of hospital beds & 350 & 547 & 754 & 310 \\
\hline Emergency room beds & 10 & 20 & 35 & 10 \\
\hline ED resuscitation rooms & 1 & 2 & $3 / 4^{a}$ & 1 \\
\hline High-care ICU beds & 13 & 25 & 52 & $12^{\mathrm{a}}$ \\
\hline Low-care ICU beds & 4 & 0 & 4 & 4 \\
\hline $\begin{array}{l}\text { Cardiac catheter laboratory } \\
24 / 7\end{array}$ & Yes & Yes & Yes & No \\
\hline Chest pain unit & 6 beds & 10 beds & 8 beds & 0 \\
\hline Stroke unit & No & No & $\begin{array}{l}18 \text { beds, supraregional } \\
\text { stroke center }\end{array}$ & No \\
\hline Trauma center & No & Level 2 (regional) & Level 2 (regional) & Level 3 (local) \\
\hline Medical specialties & 8 & 15 & 17 & 9 \\
\hline Pediatric emergency care & No & Yes, including pediatric ICU & $\begin{array}{l}\text { Only for trauma, abdominal } \\
\text { surgery ENT and urology }\end{array}$ & Yes \\
\hline Obstetrics & Yes & Yes, level 1 & No & Yes \\
\hline
\end{tabular}

endoscopy and coronary angiography. This way, anesthesia personnel and (specialized) nurses were made available for a large number of critical care SARS-CoV2 patients. Furthermore, regular wards were transformed into COVID-19 only units to enable strict separation of COVID19 cases and cases without suspicion of infection.

In all hospitals, large decreases in overall ED visits with relative reductions between $38 \%$ and $48 \%$ were detected (- Fig. 1a). In hospital number 4, electronic documentation of ED visits started within the historical control period of 2019 and therefore, the data of hospital 4 were not included in the pooled analysis. Overall, ED visits declined from 34,659 to 28,008 cases. The maximum of reduced ED visits was found in week 14 of 2020 and at the end of the study period ED visits were $17 \%$ lower compared to the corresponding week in 2019. Compared to the 14th week in 2019 medical disciplines had $56 \%$, surgical disciplines had $57 \%$ and traumatology had $51 \%$ of the case numbers. The local decline of patients varied between the hospitals that were included in the pre-post analysis (hospitals 1-3, - Fig. 1b). Patient numbers declined behind each other: hospital 3-2-1 (• Fig. 1). Outpatient ED visits dropped from 20,152 (2019) to 16,477 (2020), $p<0.001$ (• Fig. 2) but in hospital number 1 there were only a few changes in outpatient contacts. In addition, hospital admissions of ED patients declined from 14,507 to $11,531, p<0.001$ (- Fig. 2). The decrease in admissions mainly affected also non-trauma as well as surgical and trauma admissions (• Fig. 3). Admissions from ED to the ICU dropped from 2093 in 2019 to 1566 in 2020, $p=0.255$. Data of ICU admissions were mainly affected by hospital 3 with 52 ICU beds because the number of ICU admissions from the ED of hospital 3 approximately counts as much as the rest together. In hospital 3 the decline was significant $(p=0.0084)$ while in the other hospitals the numbers remained stable leading to an overall non-significant difference. Work-related accidents showed a dynamic trend in 2019 with a decrease in the spring and an increase after the Easter holidays, but the decrease in $\mathbf{2 0 2 0}$ was more profound and the curve did not recover after the Easter holidays as it recovered in 2019 after the Easter holidays: 2290 (2019) vs. 1468 (2020), $p<0.001$.

The local COVID-19 situation was as follows: in the city of Mönchengladbach, there were 650 SARS-CoV-2 positive patients in the study period of 2020, with 577 recovered patients and 41 deaths due to or related to COVID-19at the end of the study period. Structured data acquisition of in-hospital patients began on 18 March 2020 in a state-wide register [7]. Between week 12 and week 24, all hospitals treated 175 patients as SARS-CoV-2 positive inpatients. It has to be mentioned that in the hospitals of Mönchengladbach not only residents of this city were treated with COVID-19. Moreover, patients from neighboring districts (Heinsberg, Viersen, RheinKreis Neuss) including 2 patients from the Netherlands were admitted.

\section{Discussion}

To our knowledge, our study is the first one evaluating the changes in emergency care in a whole city in Europe observed during the COVID-19 outbreak. The local effects in the analyzed hospitals were very different due to the different sizes and specializations (- Table 1; • Figs. 1, 2, 3 and 4).

The COVID-19 outbreak led to significantly reduced overall emergency room visits and hospital admissions from the ED. This decrease in patients seeking emergency medical care mainly affected all medical specialties. Even though statistically not significant, the overall admissions from the ED to the ICU dropped especially in the biggest hospital of the city, although more ICU resources were available due to 


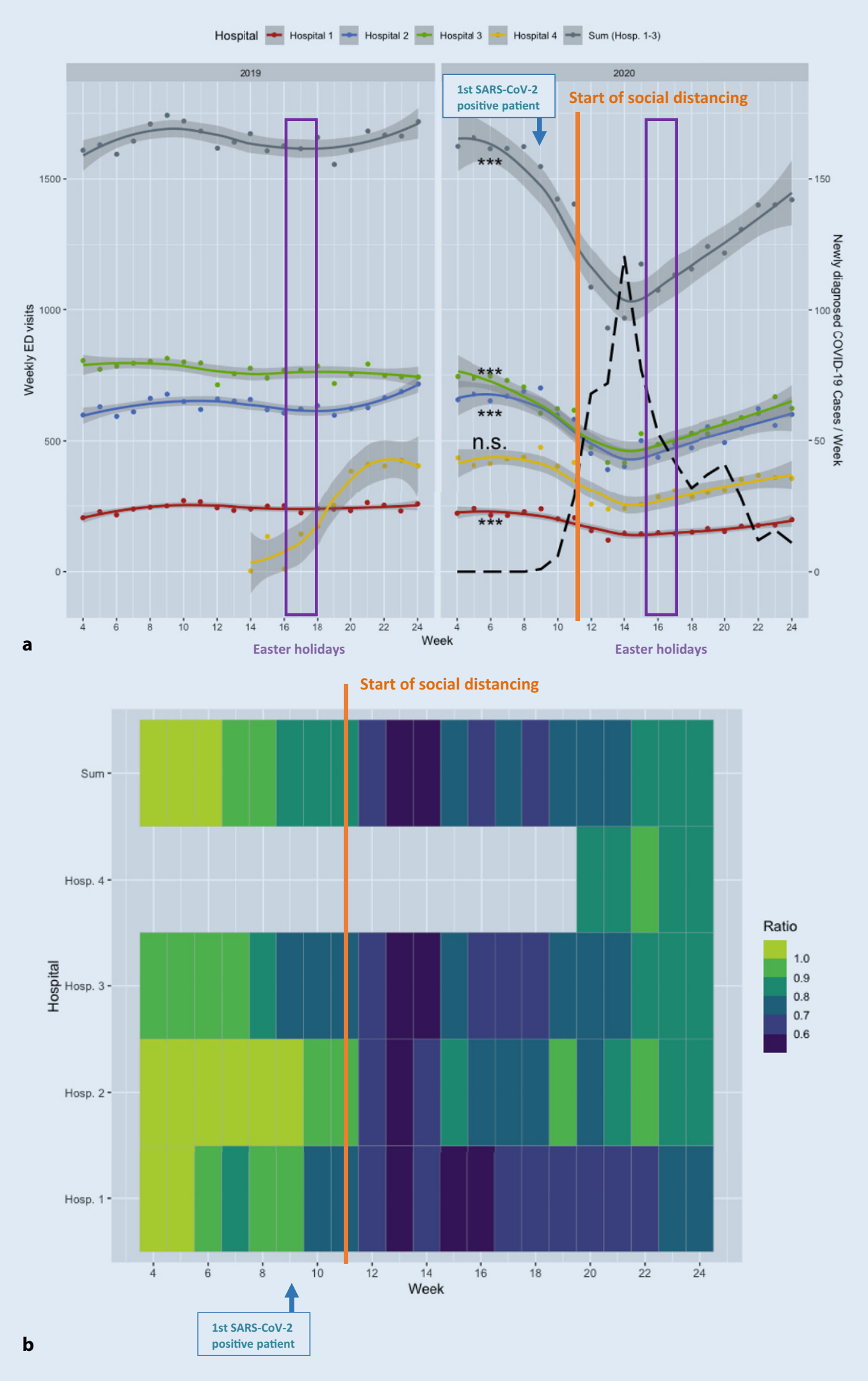

Fig. $1<$ a Weekly numbers of ED visits for all four hospitals in 2019 (left) and 2020 (right). The plotted black line shows newly diagnosed COVID-19 cases per week. Hospital 4 is not included in the sum, because electronic data acquisition began in week 14 of 2019 (shaded gray $95 \%$ confidence interval). b Relative changes in ED visits as heatmap with ratio between 2020 and 2019 per week. The plotted black line shows newly diagnosed COVID-19 cases per week ${ }^{*} p<0.05$; ${ }^{* *} p<0.01{ }^{* * *} p<0.001$; n.s. non-significant) 


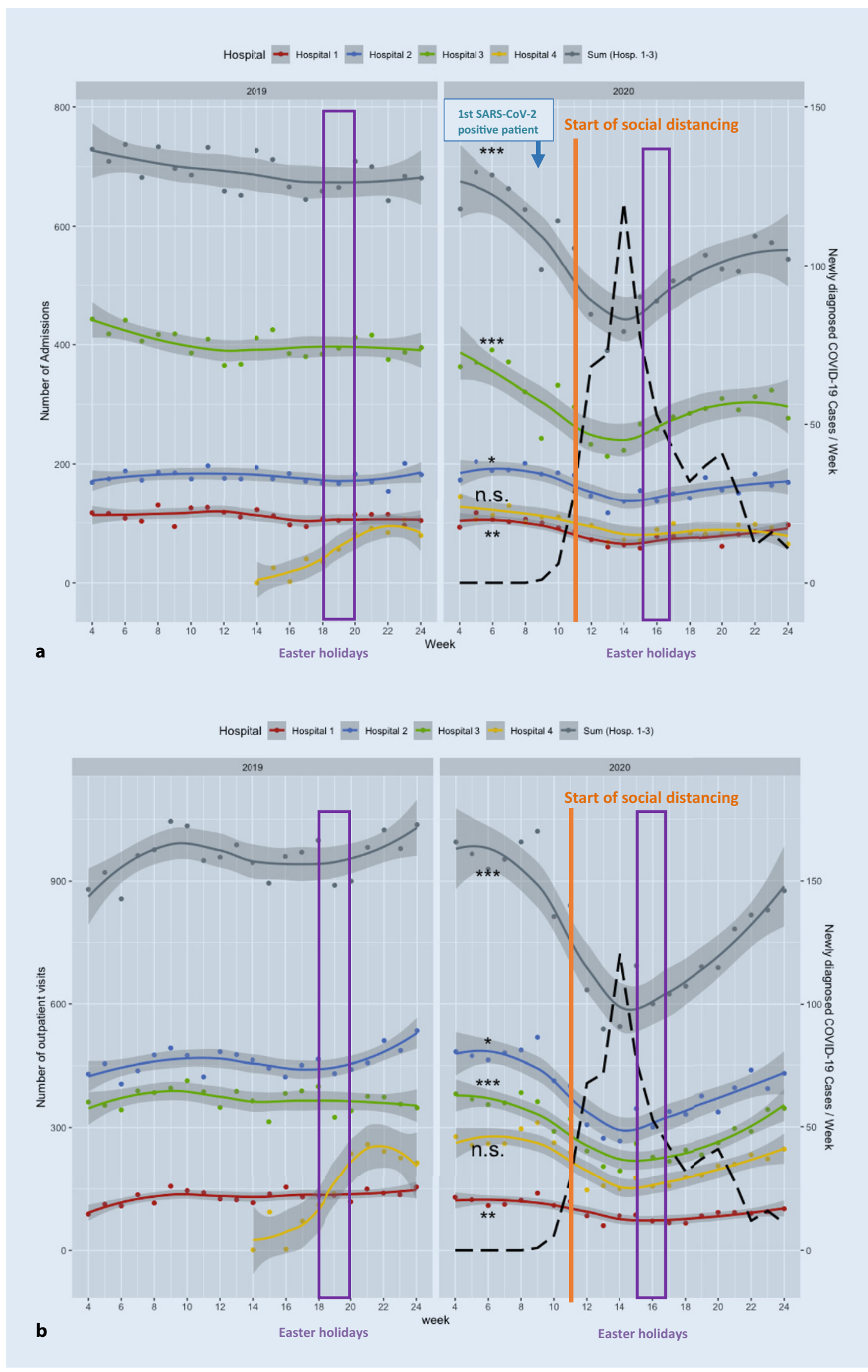

Fig. $2 \triangleleft$ Weekly numbers of hospital admissions from the ED and numbers of outpatient cases in the ED for all four hospitals (sum of hospitals 1-3) in 2019 (left) and 2020 (right). Hospital 4 is not included in the sum, because electronic data acquisition began in week 14 of 2019 . The plotted black line shows newly diagnosed COVID-19 cases per week. (shaded gray: $95 \%$ confidence interval; ${ }^{*} p<0.05$; ${ }^{* *} p<0.01{ }^{* * *} p<0.001$; n.s. nonsignificant) 


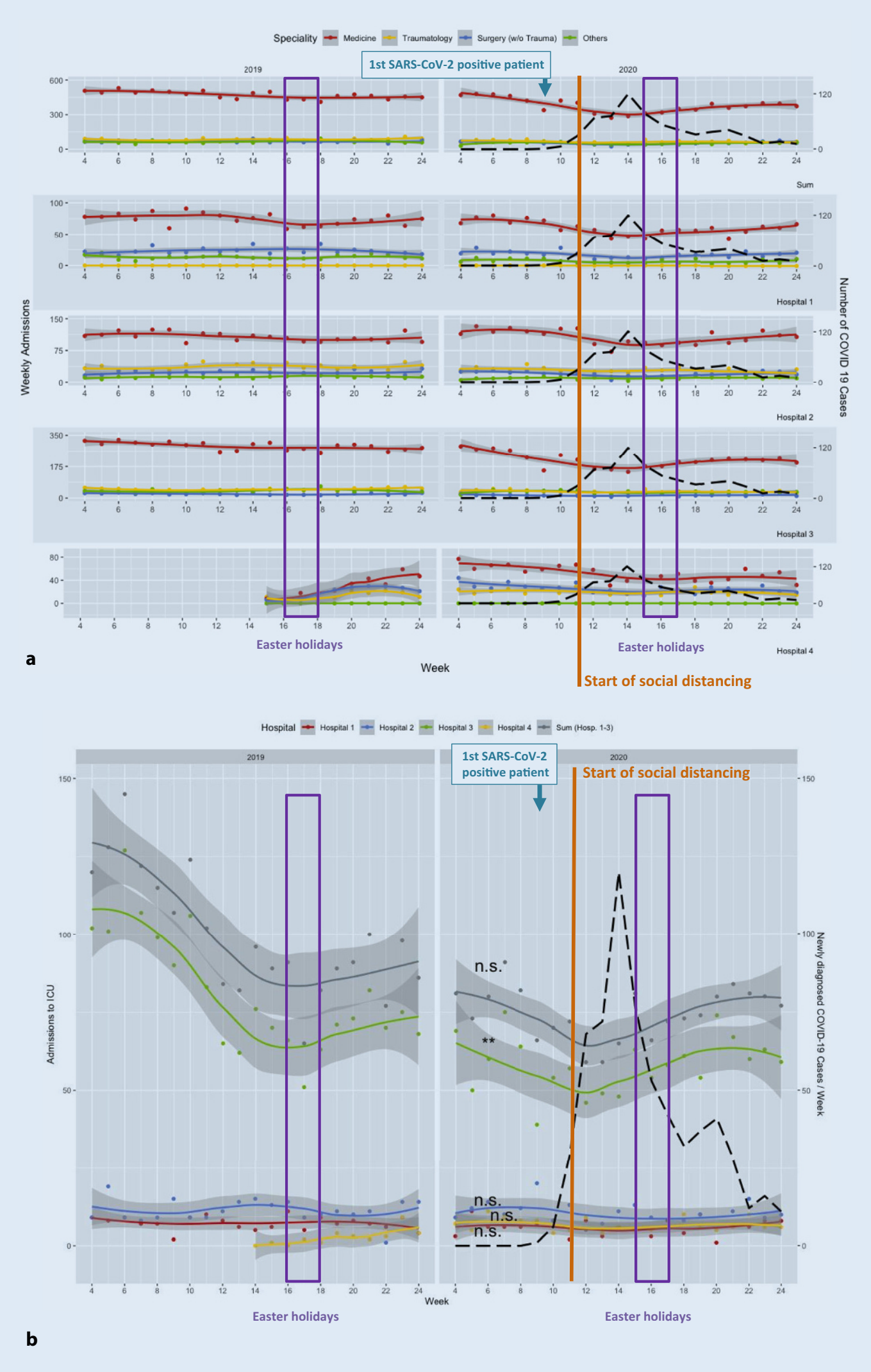

Fig. $3<$ a Grouped medical specialty of hospital admissions from the ED for the sum (hospitals 1-3) and for each hospital (shaded gray: $95 \%$ confidence interval). $\mathbf{b}$ Number of ICU admissions from the ED resuscitation room (shaded gray: $95 \%$ confidence interval; the plotted black line shows newly diagnosed COVID-19 cases per week; ${ }^{* *} p=0.0084$; n. s. non-significant) 


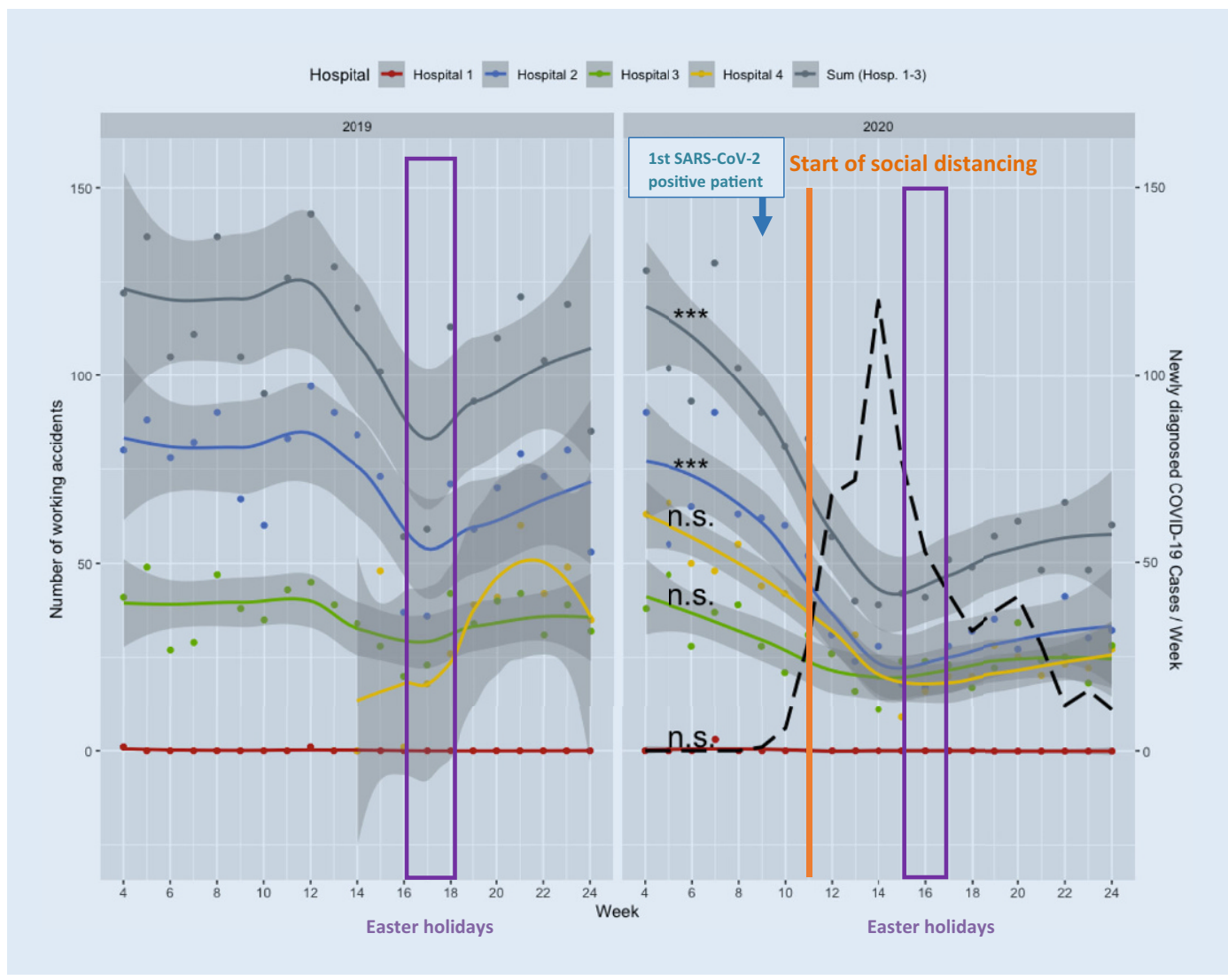

Fig. $4 \triangleleft$ Number of working accidents for each hospital and the sum (hospitals 1-3) (shaded gray: $95 \%$ confidence interval; the plotted black line shows newly diagnosed COVID-19 cases per week; ${ }^{*} p<0.05$; ${ }^{* *} p<0.01^{* * *} p<0.001$; n. s. nonsignificant)

adapted in-hospital processes. Communication between the different hospital executives, city officials and fire department executives was improved with weekly meetings during this outbreak. In all hospitals, postponement of elective procedures like operations and endoscopy were decided and executed from March 2020 on. Although hospitals are usually in competition with each other, a common strategy for a large city succeeded.

The decrease of hospital admissions and the significant decrease in ICU admissions in hospital 3 is alarming because not only outpatients with probably minor medical problems avoided ED medical care, but also inpatient numbers dropped, which is supported by the ratio of outpatients vs. inpatients that remained similar. This phenomenon, probably mostly due to the patient's fear of SARS-CoV-2, was also described by Wong et al. and led to an increased number of cardiac arrests in the California region [16].

Data from the USA also showed that reductions in ED visits were observed while admission to the hospital from ED increased between to 22 and $149 \%$ when the SARS-CoV-2 case rate began to increase [9]. The same effect was reported by Comelli et al. in Parma, Italy, in a large urban ED [3]. These findings are in contrast to our findings, but the US and Italian regions analyzed were hit much harder by the pandemic with more SARS-CoV-2 hospital admissions related to the residents. In Italy, the incidence of prehospital cardiac arrest also increased during the COVID-19 pandemic. Fear of infection with a consecutive delay in seeking medical care is also one of the possible reasons for these findings [1]. Another difference to our findings is that in a recent US supraregional study, the ED visits dropped with a latency after SARS-CoV-2 infections began to rise [2]. In the analyzed city of Mönchengladbach, ED visits declined after local media published the first local COVID-19 cases. Also in other German hospitals, reduced ED visits during the pandemic crisis were found, which is also in contrast to the USA and Italy, but data was retrieved from an ED register of mainly university hospitals, which is not completely representative [14]. In contrast to this study that included data of 36 different German hospitals in different regions, the decrease of patients seeking medical care in an ED in our study dropped 2 weeks earlier [14]. In week 9, after the first cases of SARS-CoV-2 positive patients related to an indoor carnival event (Gangelt, district of Heinsberg, Germany) were published by the local press, ED visits began to drop in our city. The local press also released that one hospital doctor in hospital 3 was infected with SARS-CoV-2 [12]. Later on the media published hospital staff infections in hospital 2 [6]. This information could be one important reason for the accelerated local drop of ED visits and earlier decrease compared to other German regions [14].

As described above, the decrease in admitted patients was equally distributed over all medical and surgical disciplines. Schwarz et al. also described reduced cerebrovascular accidents due to cardiovascular emergencies in a German university hospital, but cerebrovascular accidents did not decrease significantly [13]. Quadri et al. described reduced laboratory procedures in Italy, even for percutaneous coronary interventions [11]. This holds the risk that even patients with an urgent need for per- 
cutaneous coronary intervention do not seek cardiovascular medical care.

Overall, German data seem to be in contrast to most US data of COVID-19 hotspots where medical admissions from the ED increased and motor vehicle accidents decreased $[2,5,9]$. Also, in Israel significant reductions in ED visits were observed [4]. The reduction was even more profound compared to H1N1 epidemic in 2009 in this region [4].

Working accidents dropped also in spring of 2019, especially during Easter holiday, but recovered thereafter. In 2020 the decrease in working accidents began earlier parallel to the social distancing measures like school and nonfood store closures. A considerable number of working accidents are accidents of pupils in all kinds of schools or childcare facilities. Therefore, the closure of schools and kindergartens could be one explanation for the declined number of working accidents. Unfortunately, we were not able to differentiate between accidents at workplaces and accidents at schools. Nunez et al. report that ED visits for trauma, workplace accidents and road traffic accidents declined significantly compared to the same period in 2019 during the Coronavirus crisis at a tertiary hospital in Spain [10]. In many hospitals orthopedic trauma capacities were adapted (mainly reduced and/or re-organized) due to increased numbers of COVID-19 patients [15].

After a period with restaurant, nonfood store, and school closure, the social life in Germany came to an adapted normality during May 2020; however, the number of $E D$ visits did not recover to the number of 2019. One explanation could be that people were still afraid of being infected with SARS-CoV-2 in hospitals.

\section{Limitations}

One major limitation is that partially data of one hospital could not be included in the pooled analysis because structured data acquisition started in 2019 during the historical control period. Therefore, all sum curves are affected by this limitation. Our study is a retrospective data analysis with all its limitations, but we did not analyze any performance or outcome data.
Missing data of ED contacts and hospital admissions are very unlikely but we cannot exclude missing data completely. Contact times and length of stay in the ED could not be analyzed due to different documentation systems and different use of time stamps. Therefore, we cannot answer the question if the COVID-19 outbreak affected the ED treatment time span and turnaround times.

\section{Conclusion}

The amount of ED visits dropped significantly after the appearance of the first SARS-CoV-2 positive patients in the region and after the beginning of public interventions like social distancing. The decline in patients affected not only patients with minor medical problems but also the number of hospital admissions from the ED and even the number of patients admitted to the ICU, which contrasts with data from other countries. The decline is alarming because it reinforces the suspicion that patients with relevant medical problems did not seek medical care due to possible fear of infection. Those secondary effects of the pandemic on healthcare and the socioeconomic impact should be analyzed in further studies. For future pandemic waves or crises an improved information of patients using different media seems to be meaningful to avoid medical problems or even deaths due to delayed seeking of emergency medical care. A local information strategy using the hospital websites, local print media and radio was initiated to inform patients about in-hospital safety measures regarding SARS-CoV-2. Furthermore, an information campaign in local media together with the fire department (responsible for the EMS) is planned to avoid too late activation of EMS or avoidance of ED visits in serious medical conditions.

\section{Corresponding address}

\section{PD Dr. med. Sebastian Bergrath}

Zentrum für klinische Akut- und Notfallmedizin, Kliniken Maria Hilf, Akademisches Lehrkrankenhaus der RWTH Aachen Viersener Straße 450, 41063 Mönchengladbach, Germany

sebastian.bergrath@mariahilf.de
Funding. There was no specific funding for the conducted study.

\section{Declarations}

Conflict of interest. S. Bergrath, T. Strapatsas, M. Tuemen, T. Reith, M. Deussen, O. Aretz, A. Hohn and A. Lahm declare that they have no competing interests. Ethical standards. For this article no studies with human participants or animals were performed by any of the authors. All studies cited were in accordance with the ethical standards indicated in each case. This retrospective study was performed after consultation with the institutional ethics committee (Uniklinik RWTH Aachen, Germany) and in accordance with national legal requirements.

\section{References}

1. Baldi E, Sechi GM, Mare C et al (2020) Outof-hospital cardiac arrest during the Covid-19 outbreak in Italy. N Engl J Med. https://doi.org/10. 1056/NEJMc2010418

2. Boserup B, McKenney M, Elkbuli A (2020) The impact of the COVID-19 pandemic on emergency department visits and patient safety in the United States. Am J Emerg Med 38:1732-1736. https:// doi.org/10.1016/j.ajem.2020.06.007

3. Comelli I, Scioscioli F, Cervellin G (2020) Impact of the COVID-19 epidemic on census, organization and activity of a large urban Emergency Department. Acta Biomed 91:45-49. https://doi.org/10. 23750/abm.v91i2.9565

4. Fuat B, Hisam Z, Khetam H, Shlomo H (2020) Drastic reduction inpatient visits to the emergency department in a hospital in Israel during the COVID-19 outbreak, compared to the H1N1 2009. Int J Health Policy Manag. https://doi.org/10. 34172/ijhpm.2020.151

5. Goyal P, Choi JJ, Pinheiro LC et al (2020) Clinical characteristics of Covid-19 in New York city. N Engl JMed. https://doi.org/10.1056/NEJMc2010419

6. Gruhn A Ärztin am Elisabeth-Krankenhaus ist infiziert: Zwei weitere Corona-Fälle in Mönchengladbach bestätigt. https://rponline.de/nrw/staedte/moenchengladbach/ coronavirus-moenchengladbach-zwei-weiterefaelle-bestaetigt_aid-49272801. Accessed 26 Sept 2020

7. Information system for security in the state of Northrhine Westfalia (IG-NRW) (2020)

8. LZG.NRW Corona-Meldelage. https://www. Izg.nrw.de/inf_schutz/corona_meldelage/index. html. Accessed 40ct 2020

9. Molly MJ, Gail D, Hyung P et al (2020) Trends in emergency department visits and hospital admissions in health care systems in 5 states in the first months of the COVID-19 pandemic in the US. JAMA Intern Med. https://doi.org/10.1001/ jamainternmed.2020.3288

10. Nuñez JH, Sallent A, Lakhani K et al (2020) Impact of the COVID-19 pandemic on an emergency traumatology service: experience at a tertiary trauma centre in Spain. Injury 51:1414-1418. https://doi.org/10.1016/j.injury.2020.05.016

11. Quadri G, Rognoni A, Cerrato E et al (2020) Catheterization laboratory activity before and during COVID-19 spread: a comparative analysis in piedmont, Italy, by the Italian society of Interventional cardiology (GISE). Int J Cardiol. https://doi.org/10.1016/j.ijcard.2020.08.072 
12. Richters D, Gruhn A, Janssen S Kliniken Maria Hilf in Mönchengladbach: Klinik-Arzt mit Coronavirus infiziert. https://rp-online.de/ nrw/staedte/moenchengladbach/coronavirusin-moenchengladbach-arzt-an-kliniken-mariahilf-infiziert_aid-49207507. Accessed 26 Sept 2020

13. Schwarz V, Mahfoud F, Lauder Let al (2020) Decline of emergency admissions for cardiovascular and cerebrovascular events after the outbreak of COVID-19. Clin Res Cardiol. https://doi.org/10. 1007/s00392-020-01688-9

14. Slagman A, Behringer W, Greiner F et al (2020) Medical emergencies during the COVID-19 pandemic. Dtsch Arztebl Int 117:545-552. https:// doi.org/10.3238/arztebl.2020.0545

15. Tahmassebi R, Bates P, Trompeter A et al (2020) Reflections from London's level-1 major trauma centres during the COVID crisis. Eur J Orthop Surg Traumatol 30:951-954. https://doi.org/10.1007/ s00590-020-02724-0

16. Wong LE, Hawkins JE, Langness S et al (2020) Where are all the patients? Addressing Covid-19 fear to encourage sick patients to seek emergency care. NEJM Catalyst. https://doi.org/10.1056/CAT. 20.0193

\section{Auswirkungen der Corona-Pandemie auf innerklinische notfallmedizinische Ressourcen. Eine multizentrische Observationsstudie aller Krankenhäuser einer Großstadt der Metropolregion Rhein-Ruhr}

Hintergrund: Zu Beginn der COVID-19-Pandemie im Jahr 2020 bereiteten sich das Gesundheitssystem und die Krankenhäuser in Deutschland auf höhere Patientenzahlen insgesamt und auch auf die Aufnahme zahlreicher kritisch kranker Patienten vor. Dazu mussten Ressourcen mobilisiert und Prozesse angepasst werden, die sowohl einem neuen Patientenkollektiv als auch der bisherigen Patientenversorgung gerecht werden sollten. Als eine der ersten deutschen Großstädte musste Mönchengladbach entsprechende Maßnahmen treffen, ohne dass die genauen Auswirkungen der Pandemie auf die Zusammensetzung der Patientenpopulationen abgeschätzt werden konnten bzw. bekannt war, ob ausreichend Notfallressourcen zur Verfügung stehen. In dieser Studie wird die Inanspruchnahme der kompletten KrankenhausNotfallstrukturen einer deutschen Großstadt zu Beginn der Corona-Pandemie analysiert.

Methoden: In dieser multizentrischen Observationsstudie aller $(n=4)$ Zentralen Notaufnahmen (ZNA) einer deutschen Großstadt (Mönchengladbach, ca. 274.000 Einwohner) wurde das Patientenaufkommen in den ZNA in den Kalenderwochen (KW) 4-24 im Jahr 2020 mit dem korrespondierenden Zeitraum (KW 4-24) in 2019 verglichen. Die weitere Auswertung erfolgte sowohl für jedes einzelne Krankenhaus als auch im kumulativen Gesamtvergleich in einer logistischen Regressionsanalyse. Aufgrund der voneinander unabhängigen Auswertungen der einzelnen Krankenhäuser wurde eine Bonferroni-Korrektur für das Signifikanzniveau durchgeführt.

Ergebnisse: Die ersten regionalen COVID-19-Patienten wurden in Woche 9 des Jahres 2020 entdeckt. Die kumulative Anzahl der Patienten in der ZNA sank von $34.659 \mathrm{im}$ Jahr 2019 auf $28.008 \mathrm{im} J a h r$ 2020. Die wöchentliche Anzahl pro Krankenhaus nahm ab Woche 8 zwischen $38 \%$ und $48 \%$ pro Woche und Krankenhaus ab und begann nach Woche 16 wieder zu steigen. Die gepoolte Datenanalyse des Patientenaufkommens in der ZNA zeigte einen signifikanten Rückgang ambulanter Notfallpatienten (20.152 vs. 16.477; $p<<0,001)$, Notfallpatienten mit Bedarf zur stationären Behandlung (14.507 vs. $11.531 ; p<0,001)$ und der Arbeitsunfälle (2290 vs. $1468 ; p<<0,001)$. Der Rückgang der Einweisungen von der Notaufnahme auf die Intensivstation zeigte keine Signifikanz (2093 vs. 1566; $p=0,255$ ). Der Rückgang des Patientenaufkommens in den ZNA verteilte sich gleichmäßig auf die medizinischen Fachgebiete.

Schlussfolgerung: Der regionale COVID-19-Ausbruch führte in einer deutschen Großstadtregion nach dem Auftreten der ersten COVID-19-Fälle zu einem deutlich reduzierten Patientenaufkommen in den ZNA. Auch die Zahl von stationären Aufnahmen und Intensivaufnahmen war rückläufig, während das Verhältnis von ambulanten Notfallpatienten zu stationären Patienten stabil blieb. Daher kann davon ausgegangen werden, dass Patienten mit schweren medizinischen Problemen keine Notfallversorgung aufgesucht haben. Diese sekundären Effekte der Pandemie auf das Gesundheitswesen und die sozioökonomischen Auswirkungen sollten weiter analysiert werden.

\section{Schlüsselwörter}

COVID-19 - Notaufnahme · Ambulante Besuche · Stationäre Aufnahmen · Intensivstation · Arbeitsunfall 